\title{
The Laughter-eliciting Mechanism of Humor
}

\author{
Zhihui $\mathrm{Wu}^{1}$ \\ ${ }^{1}$ Foreign Languages Department, Zhengzhou Institute of Light Industry, No 5, Dongfeng Road, Jinshui District, \\ Zhengzhou City, Henan Province, 450002, China \\ Correspondence: Zhihui Wu, Foreign Languages Department, Zhengzhou Institute of Light Industry, No 5, Dongfeng \\ Road, Jinshui District, Zhengzhou City, Henan Province, 450002, China. Tel: 86-371-63556322. E-mail: \\ debra1980@163.com
}

Received: March 17, 2013

Accepted: March 25, 2013

Online Published: April 12, 2013

doi:10.5430/elr.v2n1p52

URL: http://dx.doi.org/10.5430/elr.v2n1p52

\begin{abstract}
The appreciation of humor is a dynamic interaction between the humor recipient and the humor object. It is a multi-geared problem-solving process in which the punch-line, which is incongruous with the body of the text, must be detected and then reconciled with the lead, in the end of which a pleasurable emotional state is obtained with the resolution of the incongruities and with the release of tension built up during the preceding intellectual effort. The laughter eliciting mechanism of humor can be summarized as: (1) The humor object contains incongruities; (2) Through script-switch or logical mechanism the incongruities are resolved. (3) Pleasure arises along with the resolution of the incongruities and with the release of tension built up during the preceding intellectual effort. Incongruities are regarded as the prerequisites of the humor, and the recipient's cooperative interpretation of the humor object - resolution of the incongruities - ensures the success of a humorous event.
\end{abstract}

Keywords: Humor object, Humor recipient, Incongruity-resolution, Laughter-eliciting Mechanism

\section{Introduction}

The topic of humor has an ancient history in the annals of mankind. It is no exaggeration to say that humor, a distinctive characteristic of mankind, has been the subject of debate for at least two or three millennia. Over the centuries, many definitions have been offered, yet there is not an agreed-upon terminology in humor research.

In the field of aesthetics, humor is depicted together with comic (or: the funny) - defined as the faculty of a humanbeing to make one laugh or to amuse - as is distinguished from other aesthetic qualities, such as beauty, harmony, or tragedy. Humor in rhetoric is regarded as an effective means or technique of expression, and is treated as one of the rhetoric devices along with metaphor, pun, hyperbole, and irony. The philosopher Quintilian (cited in Koncz, 2001 ) used the term 'rhetoric' interchangeably with 'oratory', and accordingly defined humor as an art to expel the grave emotions, such as anger, hatred, fear of the audience by exciting them into laughter. The multidisciplinary property of humor determines that there will be as many interpretations of humor as there are many people on the earth. On the other hand, humor can be understood in both a broad sense and a narrow sense. In a broad sense, humor is an umbrella-term, embodying laughter, ridicule, wit, satire, parody, irony, joke, and comedy. Longman Dictionary of Contemporary English makes a list of notes to expound humor: (1) (The ability to understand and enjoy) what is funny and makes people laugh; (2) the quality of causing amusement; (3) a state of mind; mood; (4) any of four liquids which were formerly thought to be present character. But it is still inadequate to cover what humor means. And in the narrow sense humor can be anything that humor in the broad sense covers. Humor can be 'a frame of mind, a manner of perceiving and experiencing life. It is a kind of outlook, a peculiar point of view and one which has great therapeutic power' (Mindess, 1971:21) or it can be as simple as something 'amusing yet meaningful' (Contemporary Chinese Dictionary).

Anyway, we have to abstract some common properties of humor to facilitate further illustration of the topic. A brief survey of the definition of humor suggests that the definition of humor embraces at least the following three elements:

(1) Humor is one of the most valuable traits of human beings indicating intelligence;

(2) Humor may involve witty, satirical, funny and absurd or ridiculous elements and techniques, but it is expressed in a mild and good-intended manner; 
(3) Humor elicits laughter or inward smile.

Humor not only plays a role in social communication, but also helps maintain and enhance the quality of our life. For individual persons, being humorous is always a sign of good character. We know something is funny, and we also want to know (1) why it is funny; (2) how it elicits laughter from the recipient. This study will for most of the part conduct an analytical study of humor, and try to provide answers to the above two questions. Following a literature review, an analysis of how humor processes - a dynamic interaction between the humor recipient and the humor object, will be expounded in detail. Humor object refers to those that make us laugh, which can be an action, a picture or a piece of joke. Humor recipient is the receiver or the beneficiary of humor; it can be a viewer, a hearer or a reader. Another major part of this paper will be devoted to the key issue of 'why it is funny', in which different kinds of incongruities are to be analyzed. A great many of humor and jokes collected from books or other resources will be examined to illustrate the laughter-evoking mechanism of humor.

\section{Literature review}

\section{1 Theories in humor study}

If we make a calculation, we will find more than one hundred 'theories' of humor originating from a variety of disciplines (philosophy, sociology, psychology, neurology, art, physiology, psychoanalysis, psychobiology, linguistics, anthropology, etc.). They include general theories about humor or laughter, statements of the circumstances in which humor may occur, and characterizations or descriptions of humor.

Jim Lyttle (2003) sorted the theories into three groups. The first group (superiority and the cognitive theories) tests our response, exploring how and why we find things funny. The second group (biological, psychoanalytic or relief, and ambivalence theories) studies the function of humor, explaining why we laugh and what survival value humor has. The last group (incongruity, surprise, and configuration theories) investigates the stimuli of humor, illustrating what makes things funny. In correspondence to specific theories of humor, the first group is usually associated with the notion of superiority, the second with relief, and the third with incongruity.

- Superiority Theory

The first explicit description of the Superiority Theory was probably the one given by Thomas Hobbes in his Leviathan. Hobbes (1651) regarded laughter as an expression of 'a sudden realization that we are better than others', an expression of 'sudden glory'. He explained that 'humans are in a constant competition with each other, looking for the shortcomings of other persons. The greater the dignity of the victim is, the greater the resulting amusement'. Superiority theory is of great interest to social-linguist, because in this theory the emphasis is put on the interpersonal and social aspect of humor. There are also opponents who do not agree that superiority is the central element of humor, fort there are a lot of jokes in which none is laughted at.

\section{- Relief/Release Theory}

Relief/Release Theory has a clear physiological or psycho-physiological nature. What Relief/Release Theory claims is that laughter is a relief/release of tension or nervous energy. It was probably Sigmund Freud who was most closely associated with this theory. Freud (1905) believed that it is the release and the relief as well as the pleasure derived from them that were characteristic of humor. He maintained that humor 'releases' tensions, psychic energy, or that humor 'releases' one from inhibitions, conventions and laws. However, there are also voices against this theory. Rutter (1997) argued that 'release theories are non-contextual; that is, they seek to explain all laughter through a single set of causes regardless of its time and place, history or persons involved.

\section{- Incongruity Theory}

The incongruity-based theory stresses the absurd, the unexpected, and the inappropriate or out-of-context events as the basis for humor. In contrast to the emotional pleasure-laughter, Incongruity Theory identifies amusement as an intellectual reaction to something that is unexpected, illogical, or inappropriate in some way.Philosophers argue that incongruity is at the core of all humor experiences. That is, something unexpected, out of context, inappropriate, unreasonable, illogical, exaggerated, and so forth, must serve as the basic vehicle for the humor.

The three theories actually characterize the complex phenomenon of humor from different angles and do not at all contradict with each other (Raskin, 1985: 40). They seem to be three different parts of a larger whole, supplementing each other quite nicely. Superiority Theory explains why humor is created and how some people use humor - for expressing superiority, for assigning inferiority, for alienation, for expressing different or unknown fear. Relief/Release Theory explains how our body reacts to humor (and other stimuli) through the physiological action of laughter. Incongruity Theory explains how humor is constructed and cognitively processed - it maintains that in all 
instances where humor occurs there exists a violation of expectations based on what is anticipated through the socialization we underwent (and continually undergo), and the inherent rationality of our language.

\subsection{Domestic and Foreign Humor Study}

A brief survey of domestic and foreign research on humor suggests that humor study scatter in many fields as has been mentioned previously and can be explored from angles of all elements, such as the humor initiator - the speaker, the humor carrier - the language, the humor recipient - the listener, or the bystander.

In the past two decades, with the booming of linguistics, humor is no longer a subject confined to social or psychoanalytical study. In the field of linguistics, one important figure who has made the weightiest contribution to humor study on the basis of the classical theories is Victor Raskin, with his seminal book Semantic Mechanisms of Humor (1985). Raskin presented a linguistic incongruity theory of verbal humor which stressed the switching of context. The text was centered on the 'Semantic Script Theory of Humor' (SSTH). According to him, Humor occurs if the following obtains:

\section{1) The text is compatible, fully or in part, with two different scripts and}

\section{2) The two scripts with which the text is compatible are opposite in a special sense. (Raskin 1985, p.99)}

Neal Norrick, a professor of English linguistics, who counts his interests as pragmatics and semantics, has come up with a book Conversational Joking: Humor in Everyday Talk (1993). He presented an account of joking from the perspective of contemporary discourse analysis, and more specifically on the model of conversation analysis. The terms, definitions and methods used to describe conversations were thus used to describe joking.

Another important figure is Salvatore Attardo with his book, Linguistic Theories of Humor (Attardo 1994), which is actually a survey of various linguistic theories of humor up to 1993. According to him the book is a 'necessary and sufficient condition' for anyone wishing to have a general survey of humor from the perspective of linguistics. The book has, to some extent, clearly increased our access to a variety of linguistic literature on humor.

Meanwhile, other scholars (Fauconnier 1994, 1998; Coulson, 2000) tried to explain the working mechanism of humor with the support of theories borrowed from psychology, especially cognitive ones like Set Theory, Graph Theory, and Conceptual Integration.

Humor Study in western academic circles has seen tremendous achievements, both theoretically and empirically, whereas in china the study on humor, especially theoretical research is comparatively lagged out, although Chinese people never lack in humor.

Liu Naishi, Xiong Xueliang (2003) held it that humor has the function of saving one's face. Shi Jing (1999) have dicovered that puns, as a result of homophones, homonyms or polysemes, and ambiguities, caused by the typical phonetic, syntactic, semantic, referential features of our language, slips of tongue, allusion and parody, can create humor. Wang Yan (2007) diagnosed rhetoric techniques of humor language, such as anticlimax, hyperbole, irony, transferred epithet, oxymoron, metaphor, personification, euphemism, antithesis, and zeugma.

Nan Zuoming (2000), Jiangyong (2003), analyzed humor from the perspective of semantics, maintaining that humor is the result of semantic field shift, for example the unusual meaning transmission from presupposed semantic field to actual semantic field. Chen Chunhua (1999), Li Lanping (2002), from the perspective of pragmatics, argues that violating Grice's Cooperative Principle gives rise to humor. Other researchers such as Zhu Ximing (2003), Wangyong (2001), and Wang Wenbin \& Lin Bo (2003) explained humor phenomenon from cognitive and psychological perspectives, with the support of Sperber \& Wilson's Relevance Theory and Fauconnier \& Turner's Conceptual Blending Theory.

A literature review informs us that scholars have contributed a lot to humor research. However, most current studies, their academic value of course should not be denied, are either confined to the humor initiator focusing on the techniques of humor, or to the humor object, say humor carrier - the language, focusing on the functions and features of humor. The humor recipient, for most of the part, is neglected. The root cause and the laughter-eliciting mechanism are seldom investigated. Unlike other linguistic studies of humor, we will include the humor recipients who are indispensable to the success of a humor event into the research. Meanwhile we will identify three more groups of new incongruities, namely the stylistic incongruities, the stereotypical incongruities and the behavioral incongruities, which may not be found in other works. That, to some extent, will enrich a bit the incongruity theory. 


\section{Incongruity resolution as laughter eliciting mechanism}

\subsection{Properties of humor object and humor recipient}

Humor in nature is a dynamic interaction process, requiring the participation of at least two parties: humor object and humor recipient. Sometimes it may also involve an initiator or some sort of onlookers. We mainly focus on the object and the appreciator. As the humor object, it must contain incongruities as the stimuli of laughter, and for the recipient, he/she must possess a kind of humor competence.

\subsubsection{Incongruities as the humor stimuli}

If there is one generalization that can be extracted from the literature about humour, it is that humour contains incongruity. This point, with various terminologies, has been acknowledged by numerous authors (Morreall, 1989; Paulos, 1980; Raskin, 1985). If we view the laughter-eliciting mechanism as a stimuli-response process, then the stimuli is none other than various incongruities contained in the humor object. In other words, incongruity is prerequisite of humor appreciation.

According to Random House College Dictionary, incongruous means: 1. out of keeping or place; inappropriate; unbecoming; 2. not harmonious in character; inconsonant; lacking harmony of parts; 3 . inconsistent.

In this article, 'incongruity' denotes a series of concepts such as surprise, absurdity, novelty/originality, deviation from convention and etc., and as notified by Paulos (1980), ' Incongruity is intended in a wide sense, comprising the following oppositions: expectation versus surprise, the mechanical versus the spiritual, superiority versus incompetence, balance versus exaggeration, and propriety versus vulgarity'. The clarification of incongruities will be further exemplified in the following part.

As far as the humorous text is concerned, 'the incongruity consists in the relation between the last line, or punchline, and the part that precedes the last line' (Shultz, 1976:13).

\subsubsection{Humor competence as the property of the recipient}

On the recipient's part, with which other terms like the 'appreciator' and the 'perceiver' share exactly the same meaning, there are also prescriptions.

A fundamental trait of humor recipient crucial to humor appreciation is humor competence. Humor competence is somewhat a dynamic construct, presupposing knowledge of the semantic mechanisms of humor, grammar, discourse rules, communication strategies, social norms of language use, and world knowledge. Humor competence for most part is reflected with a 'sense of humor'. A sense of humor is a frame of mind, a manner of perceiving and experiencing life, and a particular point of view which has therapeutic value (Xu Lixin, 2003). A sense of humor is also regarded as a unique aesthetic attitude of the individual, since 'aesthetic attitude' links up all the different constructions, imagination, reasoning, initiatives and emotions.

Humor appreciation is an intellectual activity. And in order to reap laughter, a playful mind-set or disposition would appear to be also necessary. Levine (1980) referred to humor as being a form of play. Humor lies in not taking things seriously (severely). To take something seriously is often to take it literally, and fail to see the double or deviant meanings, or larger perspectives. Seriousness is the killer of pleasure.

Besides the above mentioned properties, other conditions such as a cooperative spirit, development of appropriate language skills, a creative ability, and sufficient life experience to be able to relate to the situation depicted in the joke are also necessary.

\subsection{Incongruity Resolution}

Although there is a general agreement that incongruity is a necessary condition for humor, it is argued that incongruity alone is insufficient for laughter, and sheer incongruity may also lead to puzzlement and even to aversive reactions, especially amongst adults. Resolution of the incongruity means with the recipient's mental cognitive effort, the apparently incongruous representation is resolved, and the unreasonable becomes resonable, the unusual becomes acceptable.

There is no clear definition of the incongruity-resolution (abbreviated as IR) theory within the literature, but the following account may help capture the essence of the idea. The usual statement of the IR model postulates that humour is created by a multi- stage process in which an initial incongruity is created, and then with the emergence of further information the incongruity is resolved.

Suls (1972: 82) presented a two-stage model of humor appreciation that emphasized the understanding aspect. According to this model, the perceiver must proceed through two stages to find a joke or cartoon funny. In the first 
stage, '... the perceiver finds his expectation about the text disconfirmed by the ending of the joke ... In other words, the recipient encounters an incongruity - the punchline. In the second stage, the perceiver engages in a form of problem solving to find a cognitive rule which makes the punchline follow from the main part of the joke, and reconciles the incongruous parts.'

The way to resolve incongruities can be varied, owing to the multi-faced property of the incongruities as well as the complexity of the our mental activity in humor processing. Several elements in incongruity resolution are going to be analysed in the following section.

\subsubsection{Script-switch in incongruity resolution}

The notion of 'script' originated from psychology and was incorporated by Raskin into his Semantic Script Theory of Humor (henceforth abbreviated as SSTH). According to Raskin (1985: 81), a script is "a large chunk of semantic information surrounding the word or evoked by it". It is a cognitive structure internalized by the native speaker and it represents the native speaker's knowledge of a small part of the world - how a given entity is structured, what its parts and components are, or how an activity is done, a relationship organized, and so on. Every speaker has internalized quite a large repertoire of scripts of 'common sense' which represent his/her knowledge of certain routines, standard procedures, basic situations, and etc. The main claim of SSTH is that the text of a joke is always fully or in part compatible with two distinct scripts and that the two scripts are opposed to each other in a special way.

In the dynamic process of humor appreciation, "the punch-line triggers the switch from one script to the other by making the hearer backtrack and realize that a different interpretation was possible from the very beginning" (Attardo and Raskin, 1991: 308). Script switch covers the process of shifting from the original interpretation or the expectation of the text to the reinterpretation or the surprise. Humorous effect is achieved through the resolution of the incongruities.

The incongruity resolution interpreted in light of SSTH is much of a semantic cognitive perspective. Besides script switch, there also exists a conceptual-blending version of incongruity resolution, which is believed to be totally a cognitive one.

\subsubsection{Logic in incongruity resolution}

It has been frequently noted in humor research, especially since the inception of the incongruity theories of humor (Raskin, 1985: 31-36), that a joke must provide a logical or pseudological justification of the absurdity or irreality it postulates ( Attardo, 2002: 307). Logical mechanisms are defined as the operations that guide the process of incongruity resolution in humor interpretation. Speakers set up spaces to divide the information evoked by certain discourse into a series of cognitive models. Although different spaces may represent disparate information, the information contained in each individual space is logically coherent.

In humor appreciation, logical mechanisms are as inexhaustible as the number of humor cases. For the limitation of the space, we will only discuss some of them, which are considered to be salient in humor phenomenon.

- Concept Substitution

Concept substitution means that the speaker substitutes the real meaning of one concept for a specific situation, and uses it indicating another meaning which is quite different with the previous one.

- Reasoning from False Premises

In rational reasoning, we should always base our conclusion on true and solid premises, other wise the results will become invalid, and for most cases, ludicrous. Similar logical mechanisms also embrace missing link, ignoring the obvious, and etc.

\section{- Violating the Law of Ample Reasons}

The law of Ample Reasons requires that all conclusions be based on ample reasons. That is to say, we should provide enough reasons in rational reasoning from what is known to what is unknown.Similar logical mechanisms include violating the law of non-contradiction, violating the law of middle excluded, confusing likelihood and reality and etc.

Attardo (1997) argued that in the psychological incongruity-resolution models, the script opposition corresponded to the incongruity phase of joke processing, while the logical mechanism corresponded to the resolution phase.

\subsection{Humorous effect}

Incongruity resolution involves a large number of intellectual and cognitive efforts, which will eventually be 
compensated for with pleasure signaled by laughter or inward smile. That's the effect of humor. As Suls (1972) noted, 'humor derives from experiencing a sudden incongruity which is then made congruous' and laughter arises from the view of two or more inconsistent, unsuitable, or incongruous parts united in one complex object or assemblage, or acquiring a sort of mutual relation in a peculiar manner in which the mind takes notice of them.

Among funny things, some things may be funnier than others, for there are differences in degrees of humor. The degree of humor can be accounted for in terms of complexity, familiarity and intensity. Complexity seems to increase the degree of perceived humor so that if a joke contains several hidden violations, and claims for more reasoning efforts, it will be funnier than if fewer are noticed and less intellectual efforts are devoted to the incongruity resolution. Familiarity with the violation and intensity of the violation also help enhance the degree of humor. People sometimes find a situation or a joke funnier when it elicits an experience they have had before, or when the audience has had personal encounters with the violations embodied in the joke. This is because they have a vivid understanding of the violation that is occurring in the (described) situation, since they have experienced that violation in an immediate and personal way.

Humor appreciation is a multi-geared process, in which humor object, humor recipient, and a series of social, cultural and psychological elements get involved. If all elements work jointly, the humorous effect will be achieved.

Now we can summarize the laughter eliciting mechanism of humor as follows:

(1) The humor object contains incongruities;

(2) Through script-switch or logical mechanism the incongruities are resolved.

(3) Pleasure arises along with the resolution of the incongruities and with the release of tension built up during the preceding intellectual effort.

\section{Classification of incongruities in humor generation}

The incongruities identified by researchers are of three types: the cognitive, the ethical and the formal (Holland, 1982: 21). This paper will classify incongruities in another way, namely linguistic incongruities, pragmatic incongruities, stylistic incongruities, stereotypical incongruities and behavioral incongruities.

\subsection{Linguistic incongruities}

\subsubsection{Phonology-oriented incongruities}

Here we have to make a distinction between phonetics and phonology, both of which are at the sound level of language phenomenon. Phonetics focuses on the relationship between sound and human organs, explaining where sound comes from, whereas phonology studies the relationship between sound and meaning. Humor, as a typical language phenomenon, associated more with phonological features of language than with phonetic ones, especially in cases of homophony, homonymy and etc.

See the following example:

\section{(1) - Who always forgets where she puts things?}

- Miss Place.

Here, 'Miss' has two implications with the same pronunciation; one is vocatives for ladies, and the other a verb means making mistakes, a logically valid answer to the question.

\subsubsection{Lexis-oriented incongruities}

Lexis-oriented incongruities usually avail of word spellings or coinage to create humor. For example, there is a logo written as 'We Know Eggsactly How to Tell Eggs'. The advertiser deliberately uses the coined word 'eggsactly' to replace 'exactly' to attract consumers' attention. This kind of coinage is usually the purposefully wrong use of conventional words, a deviation from normality, so as to associate people with the meaning they are driving at, hence achieving humorous effect. Synonymy, antonymy, and hyponymy can also be made use of to create incongruities in humor.

\subsubsection{Syntax- oriented incongruities}

Apart from phonology-oriented incongruities and lexis-oriented incongruities, the creative use of syntactic relations in specific context also gives rise to humor.

Incongruities can be created with the same syntactic sentence structure conveying different meaning or different syntactic sentence structures conveying the same meaning: 
(2) One day I approached a building entrance behind a gray-haired, distinguished looking man. A young woman arrived at the same time and he held the door open for her. She said, 'don't hold the door for me just because I'm a lady. 'The man was silent for a moment and said, 'I didn't open the door because you are a lady. I opened it because I'm a gentleman.'

In the above joke, both the young woman and the gray-haired, distinguished looking man account for the act that 'the man opened the door for the woman' with the same sentence pattern 'the man open the door for the woman because ...' the man's version 'because I am a gentleman' is quite incongruous with the woman's 'because I am a $l a d y$ ', greatly mocking the young woman's arrogancy.

Incongruities can still be created by the gap between surface structure and the deep structure. According to the transformational-generative grammar, every sentence contains both surface structure and deep structure, if the two concepts are coincident with each other, then the speaker's intention is achieved, if not, the speaker will fail to fulfill his communicative intention. For example:

(3) A: 'But you said she sang beautifully.'
B: 'No, ldidn't.'
A: 'What did you say?'
B: 'I said she was a beautiful singer'

The word 'singer' is derived from the verb 'sing'. The sentence that causes ambiguity is 'she is a beautiful singer'. This surface structure has two Deep Structures at least (a) She sings beautifully. (b) She is a beautifully looking singer. The inconformity of two deep structures causes the humor in this joke.

\subsubsection{Semantic Incongruities}

Semantics here refers to the study of meaning as it is systematically encoded in the lexical and grammatical structure of natural language.

According to the Semantic Field Theory developed by the German linguist J. Trier, each word in a language brings to mind a certain concept or set of concepts. Concepts are not isolated, independent entities, but rather are linked to a host of related concepts in a complex 'semantic network'. A particular word tends to activate a certain region of that semantic network, which means that when a word is used, it elicits many of the concepts in the region to various degrees. This process sets our expectations for subsequent utterances, allowing us to mentally 'set the stage' for the upcoming scenario or situation.

In the language of humor, the shift of one field to another may incongruously happen, and result in a misfit of meaning. Meanwhile, the extension and the retraction of semantic filed also leads to incongruities and humor. Read the examples:

- Semantic field shift

(4) Mr. Franklin was unable to keep from running over the cat as it bolted through a bush and darted in front of his car. Picking up the door limp animal, he carried it to the house and rang the bell. A white-haired old woman answered the door. 'I'm sorry, 'said Mr. Franklin, 'but I'm afraid I've run over your cat. I'd like to replace it.' 'Certainly, 'the woman replied. 'How are you at catching mice?'

In this joke, the incongruity lies in the different scripts of the word group 'I'd like to replace it.' In the commonsense of linguistics, the word group 'sb. replaces sth.' means 'somebody replaces something with something else'. The owner of the cat in this joke is funny to assign 'Mr. Frankin would like to take the place of her cat', against common sense, to the word group 'sb. replaces sth.', so her remark - 'how are you at catching mice?' is full of humor with a criticizing tone, signaling that nothing else can compensate for her cat.

- Semantic field extension

(5) Father: Well, Tom, I talked to your teacher today and I want to ask you a question.

Who is the laziest person in your class?

Tom: I don't know, father.

Father: Oh, yes, you think! When other boys and girls are doing exercises, who sits in the classroom and only watches how other people work?

Tom: Our teacher, father. 
In the above example, the answer is technically correct, but the semantic field of 'sits in the class and only watches how other people work' is expanded to a larger domain where the teacher is included. The incongruity arises between what the father is driving at and the boy's failing to pick up what his father's intention. So the humorous effect is achieved.

- Semantic field retraction

(6) A taxi was creeping slowly through the rush-hour traffic and the passenger was in a hurry, 'please,' he said to the driver, 'Can't you go any faster?' 'Of course I can,' the cabby replied. 'But I am not allowed to leave the taxi.'

'Go' in the sentence 'can't you go any faster' triggers a semantic field where concepts like 'move' and 'drive' are equivalents, however, the cabby retracts the semantic field of 'go' to the root meaning - 'walk', thus coming the humorous remark, 'of course I can, but I'm not allowed to leave the taxi'.

\subsection{Pragmatic Incongruities}

Academically, notions of 'reference', 'presupposition', 'implicature', 'coorperative principle', and so on always fall into the categogy of Pragmatics. Accordingly, we set those incongruities relevant to the above terms apart as an indepedant section, namely the pragmatic incongruities.

\subsubsection{Reference-oriented incongruities}

Reference is, as defined by George Yule (2000), 'an act by which a speaker (or writer) uses language to enable a listener (or reader) to identify something'. The listener (or reader) will use additional information to connect what is said to what must be meant. Miss-connection of the information brings about disparity/incongruity, leading to failure in communication and liable to result in humor. Referential incongruities occur mostly in pronominal reference and deictic reference. The following example will show it.

(7) A redneck felt sick and decided to go to the doctor. The doctor examining him says "Well, I can't seem to find the problem, but I think it has to do with alcohol." The redneck replies: "Well, then, I'll come back when you're sober."

'It' is used to refer to the patient's illness, while the patient wrongly connects it to the doctor's 'can't seem to find the problem', so comes his ridiculous answer, 'I'll come back when you're sober'. Referential incongruity emerges between the doctor and the patient, and humor takes place. Needless to say, the ambiguity of pronominal reference is not new.

\subsubsection{Presupposition-oriented incongruities}

When a speaker uses referential expressions like this, he or Shakespeare, under normal circumstances, he/she is working with an assumption that the hearer knows which referent is intended. In a more general way, speakers continually design their linguistic messages on the basis of assumptions about what their hearers already know. These assumptions maybe mistaken, of course, but they underlie much of what we say in the everyday use of language. What a speaker assumes is true or is known by the hearer can be described as a presupposition.

In real communication, humor always occurs in cases where a speaker assumes something is true and hence behaves in accordance with his assumption, however, his presupposition is denied later and thus his behavior proves ridiculous. The following example may illustrate that:

(8) An old lady was strolling through the park when she saw Jamie with a dog.

'Does your dog bite?' she asked.

'No, 'said Jamie.

When the old lady tried to pet the dog; it almost bit her fingers off. 'I think you said your dog doesn't bite!' screamed the old lady with blood dripping from her hand.

'That's right, 'answered Jamie. 'My dog doesn't bite_— but that's no t my dog.'

When the old lady in the above joke asks 'Does your dog bite', she actually presupposes that the dog with Jamie is Jamie's dog - anybody will think that way, but later she is bitten by the dog, and Jamie's response denies her presupposition. The disparity between her presupposition and the truth construct a pair of incongruity, in which the old lady is fooled. 


\subsubsection{Implicature-oriented incongruities}

In actual language use, a speaker can express more than what is actually said. An implicature is anything that is inferred from an utterance. And implicature refers to the aspect of meaning that a speaker conveys, implies, or suggests without directly saying and that cannot be captured in a simple syntactic or semantic 'rule'. For example, although the utterance 'Can you pass the salt?' is literally a request for information about one's ability to pass salt, the understood implicature is a request for salt.

In communication, if the addressee tries to figure out the speaker' implicature in a way that is quite away from the truth, misunderstanding will be engendered, and humor may occur.

(9) A: Have you forgotten that you owe me ten dollars?

B: No, not yet. Give me time, I will.

A actually is implying that B should return the borrowed ten dollars to himself, while B purposefully distorts his intention. An incongruity comes into being between what is expected from $\mathrm{B}$ and $\mathrm{B}$ 's response.

4.2.4 Incongruities from violating the Cooperative Principle

Grice has identified four basic maxims subtitling the Cooperative Principle (CP) of conversation, which are believed to be the guidelines for the efficient and effective use of language. To interpret a speaker's intention, the hearer must assume that, contrary to the appearance, the Cooperative Principle is nevertheless being adhered to and the maxims being observed. For implicatures are not semantic inferences, but rather inferences based on both the content of what has been said and some specific assumptions about the cooperative nature of ordinary verbal interaction.

The four maxims are:

Quantity: Make your contribution as informative as is required. Do not make your contribution more informative than is required.

Quality: Do not say what you believe to be false. Do not say that for which you lack adequate evidence

Relation: Be relevant

Manner: Avoid obscurity of expression

Avoid ambiguity

Be brief

Be order

(Levinson 2001, p. 101)

Recipients first process the literal meaning of an utterance, assuming the speaker is adhering to the Cooperative Principle and its associated maxims, and then they check this interpretation against the context. If it fits, it can be taken to reflect the speaker's intention; if it violates any of the maxims, the recipient works out possible implicatures corresponding to what the speaker intends. The latter case, where the speaker is deliberately breaking (flouting) a conversational maxim while still being cooperative, is always a source of humor.

(10) A boastful American from Texas was being shown the sights of London by a taxi-driver. 'What's that building there?'asked the Texan.

'That's the Tower of London, sir.' replied the driver.

'Say, we can put up buildings like that in 2 weeks.' drawled the Texan.

A little while later, he said, 'And what's that building we're passing now?'

'That's Buckingham Palace, sir, where the Queen lives.'

'Is that so?'said the Texan. 'Do you know back in Texas we could put up a palace like that in a week?'

A few minutes later, they were passing Westminster Abby. The American again asked, 'Hey, cabby, what's that building over there?' 'I'm afraid I don't know, sir, 'replied the taxi- driver. 'It wasn't there this morning.'

By observing the conversational maxim of quality, one should not say what he/she believes to be false, while in the above conversation, the taxi-driver offers something false through exaggeration to mock the American's arrogance. The incongruity between the true - the Westminster Abby has been there for centuries and the false - It isn't there this morning, project onto a humor where the American is satirized. 


\subsection{Other Incongruities}

\subsubsection{Stylistic Incongruities}

Humorous effect can also be acquired through the ways words are used or the people who use them. For example, home, abode, and residence all mean 'the place where I live', yet they are not likely to be used interchangeably. When we say we are going to invite a friend home, it will be nothing unusual. But if we say we are going to invite them to our abode or residence, it must be in a joking way. The difference of the words lies in the degree of formality/informality, that is, a difference of register. Register refers to 'a style of language appropriate for a specific context' (Thornborrow, 2000: 93). A shift of register or mismatch of expressions to a context will always give rise to humor. See the following example:

(11) Governor Hunt of Wyoming visited the State Penitentiary one day, and when the prisoners assembled for the evening meal, the warden unexpectedly asked him to make a few remarks. Without thinking he began: 'Fellow citizens'. Their smiles reminded him that all of them had lost their citizenship when convicted. He tried again, 'Fellow convicts'. This was worse. As a last resort, he explained hastily, 'Well men, I don't know what to call you, but I am certainly glad to see so many of you here'.

The governor addresses the prisoner three times, 'Fellow citizens', 'Fellow convicts' and 'Well men, I don't know what to call you, but I am certainly glad to see so many of you here' respectively. However, none of the three greetings are congruous with the context or appropriate to be addressed to the prisoners. The mismatched register here gives us a lot of fun.

\subsubsection{Stereotypical Incongruities}

Stereotype is a conventional or formulaic conception or image of something or of a person that has been fixed in one's mind. The imitation of a stereotype or the parody of something is always very funny. Stereotypical incongruities refer to those images occurred to our mind with the overflow of the punchline. Those images themselves are protruding and incongruous with our common understanding of a certain kind of thing. Let's follow the example:

(12) 'Just why do you want a married man to work for you rather than a bachelor?' asked the curious chap.

'Well', sighed the boss, 'the married men don't get so upset if I yell at them.'

'Married men don't get so upset if I yell at them' touches off the stereotype of married men, who are believed to become slaves of marriage - numb and get used to yelling from their wives. But in real life, it is nine out of ten that men are not slaves of marriage. The reason provided by the boss is very interesting if not logically correct.

\subsubsection{Behavioral Incongruities}

For most of the time, the incongruities in humor are demonstrated through language, but there are also cases of humor where language plays a less important role. It's the behavior of the characters of the story that makes us laugh. See the following example:

(13) My aunt, Goldie, is known for her love of activity. Anyone who invites her out usually gets an enthusiastic 'yes!' in response.

One day her husband, John, went outside and got into the car. 'Wait!' Goldie yelled as she rounded up the kids. She quickly ran a brush through her daughter's hair and changed her son's shirt. Then, grabbing her purse, she raced through the door. As her husband waited wordlessly, she buckled the kids in the back seat and collapsed in the front. 'Okay,'she beamed at him, 'let's go.'

John took the car out of park and drove into the garage.

Goldie is guessing all the way that her husband is ready to go out; however, the husband proves not intend to go out at all but drive the car directly into the garage. The disappointing aunt becomes a laughingstock. Here in this joke, the incongruity lies in nothing but the aunt's expectation of her husband's behavior and the husband's actual behavior.

\section{Conclusion}

After all the previous efforts, we can now conclude that although humor, for its varieties in both forms and contents, can not be governed or guaranteed with a certain rule, yet the laugher-eliciting mechanism of humor can be summarized into the following three points despite their encyclopedia property: 1) Humor object contains incongruities; 2) Through script-switch or logical mechanism, the incongruities are resolved; 3) Pleasure arises along 
with the resolution of the incongruities and with the release of tension built up during the preceding intellectual effort.

Incongruity, with a lot of forms and names, answers the question 'why it is funny?' People laugh because they find something twisted, that their expectation proves to be emptied and comes out as a surprise, or that the arrogance of others is punished. Incongruity is necessary for humor, whilst it doesn't mean that with incongruity there must be the humorous effect. Then 'how does it evoke laughter from the recipient?' It is the cooperative cognitive appreciation of the humor recipient, or the joy of 'solving' the twist in the situation that is experienced as humorous. Once a stimulus is perceived as humorous, it will trigger a reaction within the individual. This reaction may be as visible as laughter, or it is just an inward smile.

Unlike other linguistic studies of humor, which gave more than enough attention to humor carrier - the language - in explaining the working mechanism of humor, we has included the humor recipients who are indispensable to the success of a humor event. Meanwhile we have identified three groups of new incongruities, namely the stylistic incongruities, the stereotypical incongruities and the behavioral incongruities, which may not be found in other works. That, to some extent, has enriched a bit the incongruity theory. With a better understanding of the working mechanism of humor, we will become more apt to humor, either as a humor initiator or a humor appreciator. Humor facilitates communication with strangers, strengthens the power of one's speech, and brings about laughter among friends. In a word, humor enhances the quality of our life.

However, despite the theoretical and practical values of the thesis, there is still much room for improvement. We study the laughter - eliciting mechanism of humor focusing only on the two most important elements: the humor object and the humor recipient. Actually a successful humor interaction involves more than two factors. Other parameters, such as the humor initiator, the context, and culture, can also be included in the future study of the working mechanism of humor.

\section{Acknowledgements}

This paper comes from the research (A Multi-dimentional Analysis of Humor Discourses in New Media Context) supported by School Research Fund (No. 2012 XJJ 030) of Zhengzhou Institute of Light Industry (ZZILI). We would like to express our gratitude to ZZILI.

\section{References}

Attardo, Salvatore, and Victor Raskin. (1991). Script theory revis(it) ed: Joke similarity and joke representation model. Humor: International Journal of Humor Research, vol.4, no.3-4, 293-347.

Attardo, Salvatore. (1994), Linguistic Theories of Humor, Mouton de Gruyter, New York.

Attardo, Salvatore. (1997). The semantic foundations of cognitive theories of humor. Humor: International Journal of Humor Research, vol.10, no.4, 395-420. http://dx.doi.org/10.1515/humr.1997.10.4.395

Attardo, Salvatore, Christian F. Hempelmann, and Dara Di Maio. (2002). Script oppositions and logical mechanisms: Modeling incongruities and their resolutions. Humor: International Journal of Humor Research, vol.15, no.1, 3-46. http://dx.doi.org/10.1515/humr.2002.004

Chen, Chunhua. (1999). Pragmatic analysis of conversational humor. Jounal of PLA Foreign Languages University,1, 21-24.

Coulson, Seana. (2000). Semantic Leaps: Frame-shifting and Conceptual Blending in Meaning Construction, Cambridge University Press, New York, pp. 37-208.

Fauconnier, Gilles. (1994). Mental space, in Chrvstopher L Nehaniv Ed. Computation for Metaphors, Analogy and Agents, Cambridge University Press, 1999, Cambridge and New York, pp.101-112.

Fauconnier, G \& Turner, M. (1998). Conceptual integration networks. Cognitive Science, 22, 133-187. http://dx.doi.org/10.1207/s15516709cog2202_1

Freud, Sigmund. (1952). Humor. In J. Strachery (Ed.), Sigmund Freud, Collected papers, Hogarth, London, pp.215-221.

Hobbes, Thomas. (1651). Leviathan: The right of nature and the problem of civil war. In Jorge Gracia, Greg Reichberg \& Bernard Schumacher, eds, The Classics of Western Philosophy: A Reader's Guide, Blackwell, Oxford, pp.234-244.

Holland, N. N. (1982). Laughing: A Psychology of Humor, Cornell University Press, New York. 
Jiang, Yong. (2003). Semantic leaps in humorous interpretations: An implicit-space-blending-theoretic approach. Shandong Foreign anguage Teaching Journal, 1, 25-31. http://dx.doi.org/ $10.3969 /$ j.issn.1002-2643.2003.01.006

Keith-Spiegel, P. C. (1972). Early conceptions of humor: Varieties and issues. In J. H. Goldstein \& P. E. McGhee (Eds.). The Psychology of Humor: Theoretical Perspectives and Empirical Issues, Academic Press, New York.

Koncz, James Robert. (2001). Rhetorically Analyzing Humor: A methodology for studying humor as a rhetorical strategy', PhD dissertation, Arizona State University.

Levinson, Stephen C. (1983). Pragmatics, Cambridge University Press, Cambridge.

Li, Lanping. (2002). Pragmatics and English Humor. Journal of Tianjin Foreign Studies University, 2, 32-36. http://dx.doi.org/ 10.3969/j.issn.1008-665X.2002.02.008

Liu, Naishi and Xiong, Xueliang. (2003). On face-saving functions of verbal humor. Foreign Language Education, 6 , 10-12. http://dx.doi.org/10.3969/j.issn.1000-5544.2003.06.003

Lyttle, Jim. (2003). Theories of Humor. Retrieved from http://myweb.brooklyn.liu.edu/jlyttle/Humor.

Mindess, H. (1971). Laughter and Liberation, Nash, Los Angeles.

Nan, Zuomin. (2000). Analysis of the semantic process of verbal humor. Foreign Languages and Their Teaching,11, $18-20$.

Norrick, Neal R. (1993). Conversational Joking: Humor in Everyday Talk, Indiana University Press, Bloomington.

Paulos, J. A. (1980). Mathematics and Humor, University of Chicago Press, Chicago.

Raskin, Victor. (1985). Semantic Mechanisms of Humor, D. Reidel, Dordrecht.

Rutter, Jason. (1997). Laughingly referred to: An interdisciplinary bibliography of published work in the field of humour studies and research. Salford Papers in Sociology, vol. 21, The University of Salford.

Suls, J.M. (1972). A two-stage model for the appreciation of jokes and cartoons: An information-processing analysis. In J.H. Goldstein and P.E. McGhee, eds. The Psychology of Humor, Academic Press, New York, pp. 81-100.

Thornborrow, J. and Shan Wareing. (2000). Patterns in Language: Stylistics for Students of Language and Literature. Foreign Languages Teaching and Research Press, Beijing.

Yule, George. (2000). The Study of Language. Foreign Languages Teaching and Research Press, Beijing.

Cambridge University Press.

Shi, Jing. (1999). Irelevant utterances in English humor. Jounal of PLA Foreign Languages University,5, 32-33.

Wang, Wenbin. (2004). Towards the on-line cognitive mechanisms involved in verbal humor interpretation. Journal of Ningbo University (Liberal Arts Edition), 2, 6-10. http://dx.doi.org/ 10.3969/j.issn.1001-5124.2004.02.002

Wang Yan. (2007). The features of humor language from rhetoric perspectives. Journal of Changsha Railway University (Social Science), 2, 188-189.

Wang, Yong. (2001). A study of humorous utterances from the perspective of relevance theory. Foreign Language Education, 1, 23-27. http://dx.doi.org/10.3969/j.issn.1000-5544.2001.01.005

Xu,Lixin.(2003). A Study on Humorous Discourse. Henan University Press, Kaifeng.

Zhu, Ximing. (2002). Psychological mechanisms and cognitive basis of conversational humor. Journal of Tongji University (Social Science Section), 4, 118-123. http://dx.doi.org/ 10.3969/j.issn.1009-3060.2002.04.021 